\title{
Instituciones fuertes para el postconflicto. Análisis de la realidad colombiana frente al ODS 16
}

\author{
Editora: Tulia Moreno Autor: A.A. V.V. Año: 2019 \\ Editorial Bonaventuriana, Ciudad: Cartagena, Páginas: 123
}

Ramón Medina Arteta'

Copyright: $\odot 2019$

Revista Internacional de Cooperación y Desarrollo.

Esta revista proporciona acceso abierto a todos sus contenidos bajo los términos de la licencia creative commons AtribuciónNoComercial-SinDerivar 4.o Internacional (CC BY-NC-ND 4.0)

Tipo de artículo: artículo resultado de ivestigación Recibido: octubre de 2019

Revisado: octubre de 2019

Aceptado: noviembre de 2019

Autor

1 Abogado de la Universidad de Cartagena, especialista en Derecho Público de la Universidad Externado de Colombia, Maestrante en Conflicto Social y Construcción de Paz de la Universidad de Cartagena. Docente investigador Universidad San Buenaventura, Cartagena. Miembro del Crupo de Investigación CIELACID de la misma Universidad. Contacto: ramon.medina@usbctg.edu.co

Orcid: http://orcid.org/0000-0002-5395-2633
Cómo citar:

Medida Arteta, R. (2019). Reseña: Instituciones fuertes para el postconflicto. Análisis de la realidad colombiana frente al ODS 16. Editora: Tulia Moreno Autor: A.A. V.V. Año: 2019, Editorial Bonaventuriana, Ciudad: Cartagena, Páginas: 123. Revista Internacional de Cooperación y Desarrollo. 6(2). 146-148 DOI 10.21500/23825014.4753

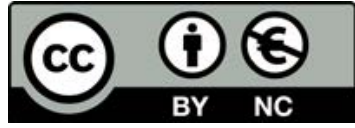

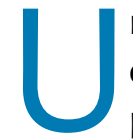
no de los principales objetos de estudio en la actualidad en el campo de la cooperación y desarrollo, por su relevancia y pertinencia, lo encontramos, sin lugar a dudas, en los análisis acerca de la implementación de la agenda global de desarrollo sostenible y, particularmente, en las medidas contenidas en los así denominados Objetivos de Desarrollo Sostenible (ODS). Si bien, las preocupaciones de la agenda global siguen enfocadas en el crecimiento económico, por primera vez se reconoce la importancia "de la paz, la justicia y el rol fundamental que desempeñan los gobiernos y las instituciones democráticas sólidas para lograr el desarroIlo". Es decir, se instala en el discurso oficial e institucional la discusión que entiende que construcción de paz y desarrollo van de la mano.

El análisis de la intersección entre los conceptos de desarrollo y paz, así como la puesta en práctica de esta agenda, reviste una especial importancia en el contexto colombiano.

Con la implementación del "Acuerdo Final" (entre el gobierno colombiano y las FARC) se busca reversar los efectos del conflicto y cambiar las condiciones que han facilitado la persistencia de la violencia en el territorio. Esto implica, por supuesto, la necesidad de transformaciones estructurales guiadas a afrontar "las raíces profundas del conflicto", arraigadas, entre otras, en condiciones históricas de exclusión, desigualdad y pobreza, de poblaciones, principalmente, vulnerables. Por ello, para diseñar futuros en los que estén presenten condiciones de paz, se debe entender que las medidas que se adopten deben estar encaminadas al desarrollo de la comunidades, sin que se "filtren" visiones de desarrollo nocivas que hagan vanas los esfuerzos por construir paz.

En ese sentido, la obra que edita Tulia Moreno es de suma importancia para entender estas discusiones. En ella se aborda la cuestión sobre la Gobernanza del desarrollo global, diseccionando el ODS 16, que tiene como fin la promoción de sociedades pacíficas 
e inclusivas para el desarrollo sostenible, facilitar el acceso a la justicia para todos, y crear instituciones eficaces, responsables e inclusivas, reflexionando sobre su aplicación en lugares específicos.

Por un lado, la obra evidencia el estado actual de los discursos y debates sobre las categorías de paz y desarrollo, proponiendo puntos de vista para entender la dicotomía que subyace en esta nueva apuesta de Cobernanza del desarrollo global, tanto en su enunciación institucional como en las críticas, que desde diferentes posturas, se le hacen a este modelo. Mientras que, por otro lado, y es uno de los elementos más interesantes de la obra, sitúa el estudio en el contexto nacional y regional que atraviesa la Colombia del post-acuerdo, analizando las dificultades y oportunidades en la implementación del mismo, a partir de variables como el enfoque de derechos humanos, cultura de paz, desarrollo, solidez institucional y cooperación internacional.

Dividido en cuatro capítulos, el libro está constituido por una multiplicidad de miradas sobre la intersección de las categorías de desarrollo y paz, vectorizadas por las metas del ODS 16. Poniendo de relieve la incidencia de la agenda global para el desarrollo sostenible en los distintos niveles de gestión y planeación territorial, incluyendo las medidas para la construcción de paz. Estos puntos de vista corresponden a los resultados de investigación de los estudiantes de la Maestría en Cooperación Internacional para el Desarrollo de la Universidad San Buenaventura, Cartagena. De ahí, que una lectura concienzuda del texto descubra una rigurosidad metodológica y disciplinar que se agradece en una obra de este estilo.

De esta manera, el primer capítulo aborda la relación que existe entre paz y desarrollo, particularmente en relación con la categoría denominada cultura de paz. Para ello, los autores llevan a cabo una laborosa tarea de delimitar conceptualmente las categorías anticipadas. Posteriormente, a partir de un análisis hermenéutico, los autores se centran en analizar la relación de la categoría de desarrollo en la idea de cultura de paz desde los escenarios institucionales 0 académicos, localizando los discursos o modelos de desarrollo que se hacen presentes, para determinar cuál predomina.

Por su parte, en el capítulo segundo, los autores ponen de manifiesto los mecanismos de control social desplegados por los paramilitares y Crupos Armados Organizados (GAO) en la subregión Sur de Bolívar, de la región Caribe colombiana. De esta manera, evidencian la reconfiguración social, política y económica de la subregión, a partir de "los repertorios de violencia" desplegados por estos grupos en la subregión, que sumada a una debilidad institucional, permitió que se afianzaran las bases de su dominación, profundizando las consecuencias del conflicto. Así mismo, se muestra cómo estos factores podrían afectar las medidas de construcción de paz territorial en la zona.

En el capítulo tercero, las autoras analizan los obstáculos y dificultades de la construcción de paz territorial en la subregión Sur de Córdoba, en el contexto del ODS 16, debido al accionar de los GAO en los municipios que la conforma. Los hallazgos de las autoras determinan que la presencia de los actores armados en el territorio corresponden, por un lado, a la histórica "presencia diferenciada" del Estado en el territorio, ya que no actúa como garante del desarrollo de la población, que vive en condiciones precarias, y por otro, a los niveles críticos de desempeño institucional, desempeño a la justicia y pésimas capacidades institucionales. De tal manera que mientras no se fortalezcan las instituciones estatales, haciendo presencia e incidencia efectiva en los territorios, los CAO serán una amenaza que multiplicará su poder y obstaculizará el desarrollo de la subregión. 
Por último, en el capítulo cuarto del texto se propone la conjunción de la cooperación internacional con el concepto del Enfoque Basado en Derechos Humanos (EBDH), en el sentido que este último sea incorporado en cada una de las fases de los proyectos de cooperación. Lo anterior, particularmente referido a la labor que realizan las organizaciones encargadas de ejecutar proyectos de desarrollo. Por ello, se parte en primer lugar de una delimitación conceptual del EBDH, que parte de una concepción particular del concepto de derechos humanos, para luego, establecer una suerte de manual de uso del EBDH en cada una de las fases del ciclo de proyecto. Finalmente, se analiza el EBDH a partir de la experiencia de la organización CORDUPAZ, que ejecuta proyectos de cooperación y desarrollo. En este apartado se muestran los resultados de aplicación de un instrumento metodológico que da cuenta del cumplimiento del EBDH en el ejercicio de sus actividades como organización.

En síntesis, se trata de una obra donde convergen distintas miradas para analizar tanto la relación entre desarrollo y paz, como la implementación del ODS 16 en el contexto particular de construcción de paz territorial en Colombia. En todo caso, no se trata de un texto definitivo que viene a cerrar todas las discusiones sobre el tema, lo cual sería inapropiado y antitécnico. Por el contrario, plantea una serie de interrogantes que sin lugar a dudas enriquecerán aún más el debate con propuestas e interpretaciones que hacen significativos aportes al debate. 